IP Periodica Polytechnica Civil Engineering

\author{
59(3), pp. 267 278, 2015 \\ DOI: $10.3311 /$ PPci.7728 \\ Creative Commons Attribution (1) \\ RESEARCH ARTICLE
}

\section{The Influence of Ambient Temperature on RC Tank Walls Watertightness in Research and Theory}

\author{
Mariusz Zych
}

Received 24-09-2014, revised 29-03-2015, accepted 30-03-2015

\begin{abstract}
The article presents a detailed comparison of two calculation models with Eurocode Standard guidelines. The stress has been put on defining the amount of reinforcement necessary to reduce the width of cracks resulting from imposed deformations in various ambient conditions. With the help of different approaches, the article presents the influence of the atmospheric factor on crack occurrence and crack width. Moreover, the calculation results are compared with the actual cracking during experimental investigations of $R C$ tank wall segments. Adopting this approach it was possible to evaluate the efficiency of calculation models pertaining to the analysis of the influence of imposed deformations on cracking in maturing concrete. The way of crack calculation defined in Eurocode Standard, in case of tank walls concreted in the first stage, leads to underestimating crack width in comparison with the crack width observed during experimental investigations.
\end{abstract}

\section{Keywords}

Codes of practice and standards $\cdot R C$ tank $\cdot$ thermal cracking . maturing concrete $\cdot$ imposed deformation $\cdot$ restrained stress

\footnotetext{
Mariusz Zych

Department of Prestressed Structures, Cracow University of Technology, Warszawska 24, 31-155 Kraków, Poland e-mail: mzych@pk.edu.pl
}

\section{Introduction}

The direct cause of semi-massive RC tank walls cracking is the decrease in wall temperature after a rapid hydration process [1]. Early-age cracking could be avoided by application of air cooled pipes [2]. The degree of temperature decrease in walls depends, among other things, on weather conditions which accompany the construction process. Moreover, ambient conditions are the most difficult factors to predict for a designer and a contractor. Eurocode Standard [3] guidelines define the way of providing reinforcement taking into account imposed strain in two element types, i.e. those restrained on two opposite ends or those restrained only by their foundation. With regard to the latter option, "it has not been studied so systematically and there appears to be little published guidance". One of the first studies on walls restrained along the bottom edge was conducted by Stoffers [4]. During his experiments deformations were not induced by temperature change but by controlled uploading of a post-tensioned beam. Owing to a large number of tested elements with various percentage and various distribution of reinforcement, crack morphology was presented depending on reinforcement percentage and the curvature of a given element. However, the elements had small dimensions and were made of micro-concrete, i.e. concrete with scaled-down granulometric composition. This concrete had an average compressive strength of about $30 \mathrm{MPa}$. Other researchers Rostásy and Henning [5], Ivanyi [6] Paas [7] formulated models to calculate the crack width in the walls restrained along their bottom edge (based at least partially on experimental investigations [4] adopting in their models the possibility of crack occurrence spaced at $(1 \div 1.5) H$. These models show the percentage of reinforcement needed to satisfy the condition of watertightness, i.e. limitation of through cracks to the value of $w_{\text {lim }}$. ACI 207.2R-95 [8] and ACI 207.2R-07 [9], present the mechanism of crack development which depends on the wall height to length ratio. It should be emphasised that this approach focus on the mechanism of cracking, but not on the problem of watertightness as these structures have a low percentage of reinforcement. Zych [10] analyses various engineering models in terms of crack formation caused by imposed deformation in RC walls, comparing 
the achieved results with the measurements performed in a natural scale on several tanks. To predict early-age cracking for massive RC structures a finite element modelling is also used [11], [12]. This article also presents a detailed comparison of the model given in Eurocode Standard [3] with two selected models [5] [6] which predicted the most accurately crack widths observed in the experiments [10]. According to CEN [3], in all structures cracking shall be limited to a specified value that will be proper for functioning or durability of the structure. Retaining structures are classified with respect to the degree of protection against leakage required. To fulfil these requirements an appropriate limit of crack width should be selected. The aim of this article is to show the influence of the ambient temperature on crack occurrence and crack width. Moreover, the evaluation of the efficiency of calculation models pertaining to the analysis of the influence of imposed deformations on cracking in maturing concrete is presented. The calculation results were compared with the crack width occurring during the RC tank construction.

\section{Assumptions of ambient temperature}

The object of the calculations are segments of an RC cylindrical tank with a unit capacity of $8300 \mathrm{~m}^{3}$, presented in detail in [13]. The calculations were made in various ambient temperatures, checking the influence of this factor on the possible state of cracking. The tank wall was divided into ten equal segments, concreted as free on the vertical edges and as restrained by the foundation. Concrete in each individual segment matured in different ambient conditions. This resulted in a varying level of cracking in individual segments. The thickness, height and length of the segments were $0.45 \mathrm{~m}, 5.5 \mathrm{~m}$ and $13.8 \mathrm{~m}$, respectively. The width and height of the foundation were $1.7 \mathrm{~m} \mathrm{x}$ $0.6 \mathrm{~m}$.

For the calculation of strains, stresses and the necessary amount of reinforcement three variants of ambient temperature were adopted, as shown in Fig. 11. In cases 1, 2 and 3 different initial ambient temperatures were assumed at the time of wall concreting. There were also different temperatures of concrete mixture, equalling 12,19 and $26^{\circ} \mathrm{C}$ accordingly (Figs. $1 \mathrm{a}$ and $1 \mathrm{p})$. In the first case, the lowest initial concrete and ambient temperatures were assumed, i.e. $12^{\circ} \mathrm{C}$. Such a temperature reflects spring weather conditions. This case also assumed that, since the wall concreting moment, the average daily temperature rise by $7^{\circ} \mathrm{C}$ during 2.5 days, and that it changes cyclically through night and day from $7^{\circ} \mathrm{C}$ to $19^{\circ} \mathrm{C}$. In the second case reflecting spring-summer weather conditions, the initial ambient and concrete mixture temperature equalled $19^{\circ} \mathrm{C}$ and temperature fall reached $7^{\circ} \mathrm{C}$. Thus, in the second case, ambient temperature was stable and its cyclical changes reflect day-night change. In the third case, the highest initial ambient and concrete mixture temperatures were assumed and they equalled $26^{\circ} \mathrm{C}$, which reflected summer weather conditions. This case also assumed that, since the wall concreting moment, the average daily temperature fall by $7^{\circ} \mathrm{C}$ during 2.5 days, and that it changes cyclically through night and day like in case 1 and 2 . All in all, case 1 reflects the concreting at the lowest ambient temperature and its gradual increase during concrete hardening. Case 2 reflects stable weather conditions. Case 3 reflects the concreting at a higher ambient temperature and its gradual fall during concrete hardening. It must be mentioned that ambient conditions are associated not only with air temperature changes, but other climatic actions like solar radiation, air humidity and wind. These factors may have the influence on the temperature fields.

The concrete used in the calculations was compatible with the concrete mix used in the construction of the reservoir in question. Cement CEM II/B-S 32,5 R of moderate heat of hydration with blast furnace slag addition was used. In the calculation of wall temperature changes, the following thermophysical parameters of concrete were adopted: $\lambda_{b}=2.6 \mathrm{~W} / \mathrm{mK}$, $c_{b}=0.77 \mathrm{~kJ} / \mathrm{kgK}$, and the thermal conductivity of the formwork $\lambda_{d}=0.2 \mathrm{~W} / \mathrm{mK}$. Consequently, the resistance of heat transfer through the formwork was $R_{d}=0.11 \mathrm{~m}^{2} \mathrm{~K} / \mathrm{W}$. Moreover, the heat transfer coefficient from the surface of the concrete was $\alpha_{e}=5.8 \mathrm{~W} / \mathrm{m}^{2} \mathrm{~K}$. The presence of the formwork was taken into account by the use of Eq. (1). In addition, the most unfavourable time of formwork removal was assumed, i.e. one day after concreting, when the temperature of the wall was the highest (Fig.1p).

$$
\alpha=\alpha_{e} /\left(R_{d} \alpha_{e}+1\right)=3,5 \mathrm{~W} / \mathrm{m}^{2} \mathrm{~K}
$$

To find the temperature fields in the wall segment Fourier's Eq. (2) was used. It is a differential equation which describes a linear flow of heat. The calculated average temperature changes in a wall cross-section are shown in Fig. 1 p

$$
\begin{gathered}
\frac{\partial T}{\partial t}=a_{b}\left(\frac{\partial^{2} T}{\partial x^{2}}+\frac{\partial^{2} T}{\partial y^{2}}+\frac{\partial^{2} T}{\partial z^{2}}\right)+\frac{1}{c_{b} \cdot \gamma_{b}} C \frac{\partial Q}{\partial t} \\
\text { initial condition: } T(x, 0)=T_{p} \\
\text { boundary condition: }\left.\frac{\partial T(x)}{\partial \eta}\right|_{k}=-\frac{\alpha}{\lambda_{b}}\left(T_{k}-T_{0}\right)
\end{gathered}
$$

where: $T_{o}$ - ambient temperature $\left[{ }^{\circ} \mathrm{C}\right]$ (Fig. 11 ) , $T_{k}$ - temperature on the element's surface $\left[{ }^{\circ} \mathrm{C}\right]$.

Generally, in Standard Codes maturity laws are used, also called equivalent time laws. The calculations include the equivalent age of concrete in the structure in accordance with Eurocode Standard [14], (Eq. [5], Fig. 27)

$$
t_{T}=\int_{0}^{t} \exp \left[-\left(\frac{4000}{273+T(t)}-13,65\right)\right] d t
$$

In the case of young hardening structures subjected to the risk of cracking tensile strength is the most important parameter. In Eurocode Standard [14] the relationships between splitting, bending or axial tensile strength and compressive strength of cubes or cylinders are mentioned. However, the type of 


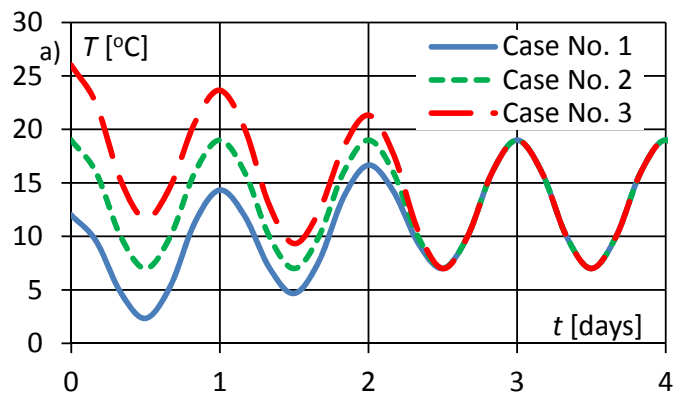

(a)

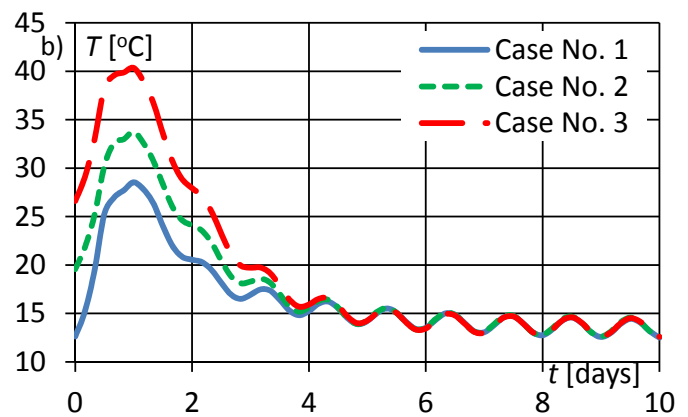

(b)

Fig. 1. a) Ambient temperature, b) average wall temperature for different

binder and the type of aggregate play the major role and this is why it is difficult to consider any concrete mix in one universal equation [15]. A correct model of mechanical behaviour is the most important in performing an accurate thermal stress analysis. Fig. 2p shows the development of tensile strength and elastic modulus of concrete, as a relative value, taking into account the equivalent age. $E_{c m, 28}=22.53 \mathrm{GPa}$ and $f_{c t m, 28}=1.86 \mathrm{MPa}$ obtained from material researches [10] were adopted in the calculations. The effect of self-equilibrating stresses was considered by reducing $f_{\text {ctm }}$ by a coefficient $k=0.895[14]$.

\section{Development of strains and stresses}

According to Eq. [6], free thermal strains changes in time were determined for individual cases of ambient temperature (Fig. 3a). In the unfavourable ambient temperature when the maximum wall temperature is the highest and later the wall temperature decrease is the biggest (i.e. case No 3), these strains reached the value of $150 \mu \varepsilon$. In turn, Fig. 3b shows the change in free strain of drying shrinkage and autogenous shrinkage (for each case), calculated after [14]. The total (mean) shrinkage strain after 10 days of concrete hardening reached $22 \mu \varepsilon$. With the assumption of the thermal expansion coefficient $\alpha_{T}=$ $11 \cdot 10^{-6}\left(1 /{ }^{\circ} \mathrm{C}\right)[16][17]$, it is an equivalent to a temperature change of $2^{\circ} \mathrm{C}$ only. It should be emphasised that the assumption of an average shrinkage strain is a considerable simplification [18], [19].

$$
\varepsilon_{\text {free }}(t)=-\alpha_{T}\left[T_{p}-T(t)\right]
$$

where: $T(t)$ - concrete temperature in time $t\left[{ }^{\circ} \mathrm{C}\right]$ (see Fig. 1]), $T_{p}$ - initial temperature of the concrete mix for $t=0\left[{ }^{\circ} \mathrm{C}\right]$ (see Fig. 1p).

Eurocode Standard [3] generally state that " $\varepsilon_{\text {free }}$ is the strain which would occur if the member was completely unrestrained". Consequently, simplified engineering calculations should use expression (7) instead of (6), neglecting in this way the strains of opposite sign induced during the temperature increase in concrete (see Fig. 3 a - Eq. (7))

$$
\varepsilon_{\text {free }}(t)=-\alpha_{T}\left[T_{\max }-T(t)\right]
$$

cases of computing. (Cases 1, 2 and 3 reflect average daily ambient temperature change by $+7,0$ and $-7^{\circ} \mathrm{C}$ taking place during the concrete hardening phase).

where: $T_{\max }$ - maximal temperature of the wall one day after concreting $\left[{ }^{\circ} \mathrm{C}\right]$ (see Fig. $1 \mathrm{~b}$ ), $T(t)$ - concrete temperature for $t>1$ day $\left[{ }^{\circ} \mathrm{C}\right]$ (see Fig. $1 \mathrm{~b}$ ).

Restrained strains, considered in the determination of the necessary amount of reinforcement, take the form of $\varepsilon_{r}(t)=$ $R_{a x} \cdot \varepsilon_{\text {free }}(t)$ (CEN, 2006 [3]). The restraint coefficient $R_{a x}=0.5$ after [20], includes the effect of creep in maturing concrete to reduce restrained strains. The resulting stress $\sigma_{r}$, then, is described by the formula $\sigma_{r}(t)=R_{a x} \cdot \varepsilon_{\text {free }}(t) \cdot E_{c m}(t)$, (where: $\varepsilon_{\text {free }}(t)$ after Eq. (7)). The development of restrained stresses calculated by this expression and the development of concrete tensile strength are shown in Fig. 4 . It should be noted that this expression does not include the effect of strain history on the current stress.

According to Eq. [8] [21], to determine imposed stresses the strain history as the sum of quotients of the current elastic modulus, strain augmentation and the influence of stress relaxation must be included. In the equation the full degree of restrained deformations, i.e. $R=1.0$ is assumed. This refers to the lower parts of the walls restrained by the foundation, and its extent depends on the wall length and foundation stiffness. Fig. $4 \mathrm{~b}$ presents the values of $\sigma_{r}$ for the analysed cases, including the creep coefficient after [14]. Considering a significant simplification [3], the compatibility of the results $\left(\sigma_{r}\right)$ with the actual approach is very good, and the simplified method seems to be an excellent engineering tool. Shrinkage stresses presented in Figs. $4 \mathrm{a}$ and $\mathrm{b}$ were calculated for the sum of autogenous shrinkage and drying shrinkage (Case No.2) under identical assumptions like in the case of thermal stress.

$$
\sigma_{r}(t)=\alpha_{T} \sum_{t_{0}}^{t} E(\tau) \Delta \bar{T}(\tau) \frac{1+\varphi(t, \tau) \cdot(\kappa-1)}{1+\kappa \cdot \varphi(t, \tau)}
$$

where: $\kappa-0.8, \varphi(t, \tau)$ - creep functions described according to [14], $\Delta \bar{T}(\tau)$ - temperature changes calculated based on Fig. 1 , $\alpha_{T}=11 \cdot 10^{-6}\left[1 /{ }^{\circ} \mathrm{C}\right], E(\tau)$ - Young's modulus (see Fig. 2p).

During contraction of the wall concrete there appear some tensile forces and bending moment, called restrained force and restrained moment. Compressive force and bending moment also appear in the foundation. All these forces must be in equi- 


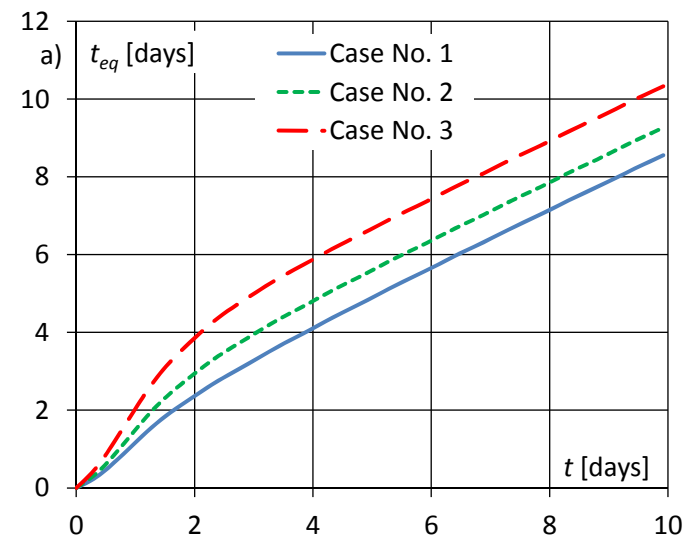

(a)

Fig. 2. a) Equivalent age of concrete, b) development of $f_{c t m}$ and $E_{c m}$ in the structure for individual cases of computing. (Cases 1, 2 and 3 reflect average

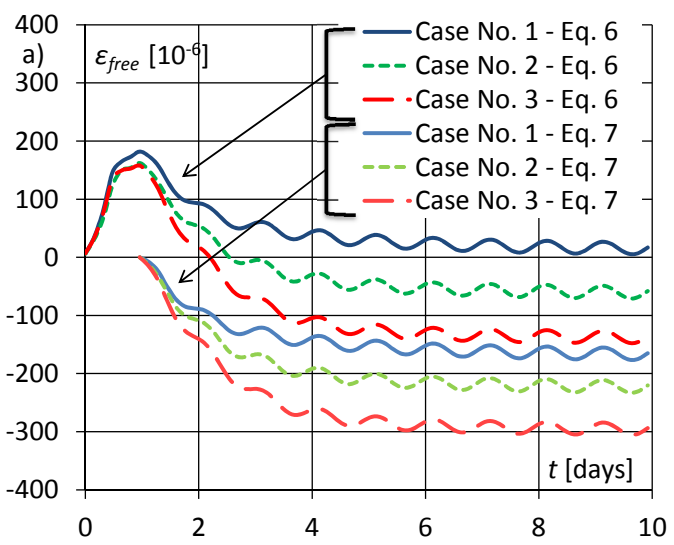

(a)

Fig. 3. Free strains: a) thermal, b) shrinkage for individual cases. (Cases

librium. Based on these forces, the tensile and compressive strains in the wall and foundation could be calculated. Assuming $L / H \rightarrow \infty$ or at least $L / H \geq 2$, there were found [5] the relationships (9) (10) between the restraint actions $N$ and $M$ depending on $S_{B}(t)=E_{W}(t) \cdot I_{W} / E_{F} \cdot I_{F}, S_{D}(t)=E_{W}(t) \cdot A_{W} / E_{F} \cdot A_{F}$ and slenderness ratio $p=\left(H+H_{F}\right) / H$ as a function of time. On the basis of $S_{B}(t), S_{D}(t)$ a greater influence of the foundation on restrained deformation in the initial stage of concrete hardening in the segment can be concluded. After three days, these parameters are subject to relatively small changes

$$
\begin{aligned}
& N(t)=-\varepsilon_{0}(t) E_{w}(t) A_{w} \cdot \\
& \cdot\left(\frac{1+S_{B}(t)}{3 p^{2} S_{b}(t)+\left(1+S_{b}(t)\right) \cdot\left(1+S_{D}(t)\right)}\right) \\
& M(t)=-\frac{1}{6} \varepsilon_{0}(t) E_{w}(t) A_{w} H \cdot \\
& \cdot\left(\frac{3 p S_{B}(t)}{3 p^{2} S_{b}(t)+\left(1+S_{b}(t)\right) \cdot\left(1+S_{D}(t)\right)}\right)
\end{aligned}
$$

where: $\quad A_{w}-$ area of wall cross section $\left(5.5 \mathrm{~m} \cdot 0.45 \mathrm{~m}=2.475 \mathrm{~m}^{2}\right), \quad E_{F}=22.53 \mathrm{GPa}$ Young's modulus of the foundation, $E_{w}(t)$ - Young's modulus of the wall (see

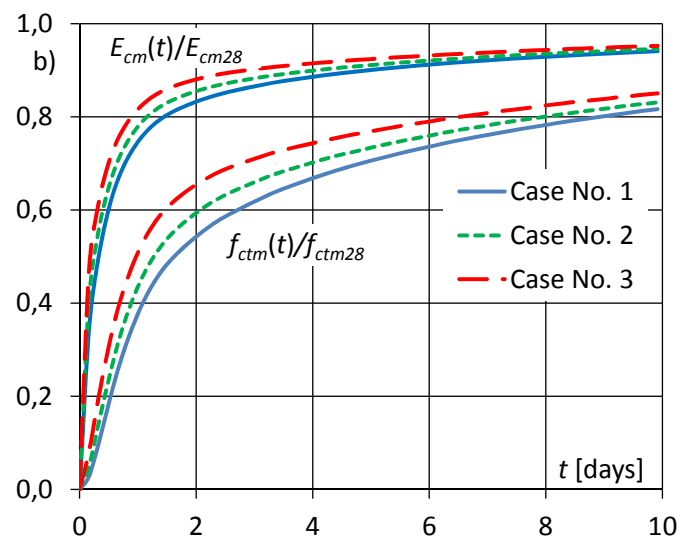

(b)

daily ambient temperature change by $+7,0$ and $-7^{\circ} \mathrm{C}$ taking place during the concrete hardening phase).

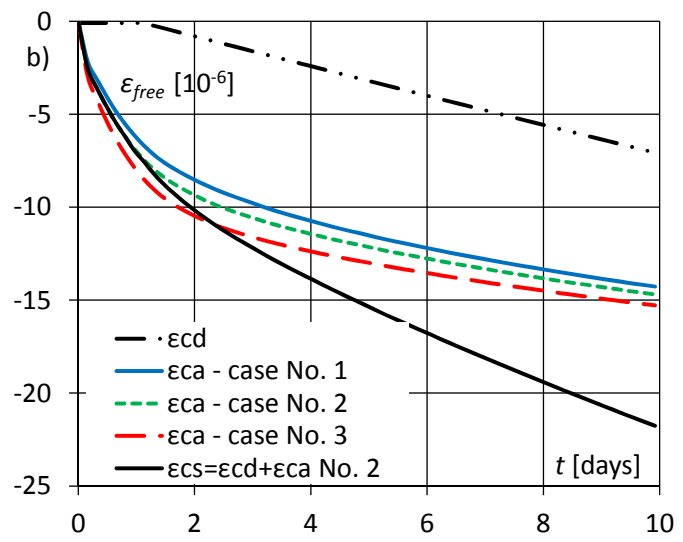

(b)

1,2 and 3 reflect average daily ambient temperature change by $+7,0$ and $-7^{\circ} \mathrm{C}$ taking place during the concrete hardening phase).

Fig. 2p), $\varepsilon_{o}-$ was adopted $=-\alpha_{T}\left(T_{\max }-T(t)\right)$ (see Eq. (7) and Fig. 3a).

In the present case, the internal forces $(N, M)$, dependent on daily temperature changes are stabilised after a period of five to six days, while a small influence of shrinkage increases continuously (Figs. 5a, b).

It should be emphasised that the nature of cracking caused by a uniform load in the cross-section and the nature of cracking caused by a self-equilibrating stresses load, that is shrinkage, are completely different [22]. A significant temperature decrease in the wall results in a few cracks through the entire thickness of the wall. These cracks are of significant length and width. After a few weeks, the self-equilibrating stresses from drying shrinkage are so large that in addition to the widening of existing cracks, new cracks appear. This stage is characterised by numerous small surface cracks developed in much smaller spacing. These cracks do not affect the watertightness of the tank.

Next, the development of the stresses at the bottom, top edge of the wall and halfway its height were calculated (Fig. 6) as a function of $N$ and $M$. On this basis, the criterion of cracking was 


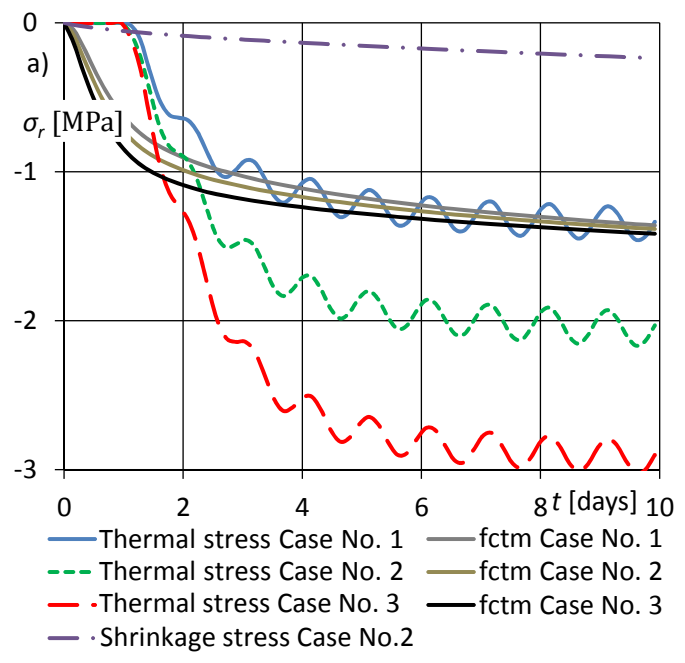

(a)

Fig. 4. Development of stress for individual cases of ambient temperature and shrinkage after: a) Eurocode Standard [3], b) Eq. 8]. (Cases 1, 2 and 3

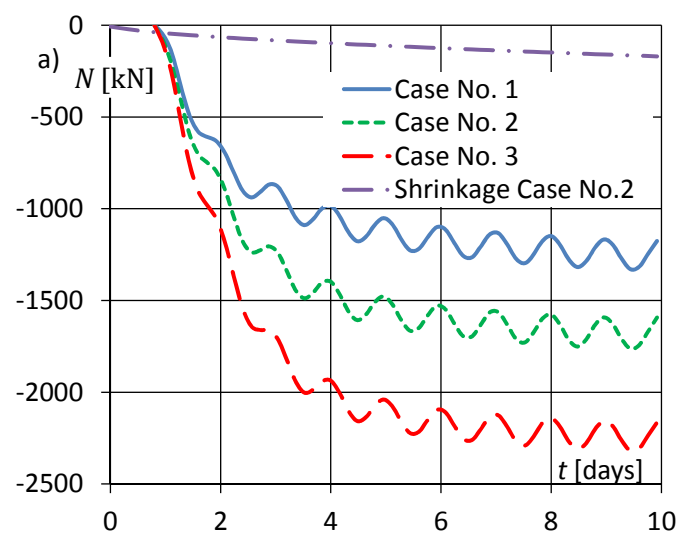

(a)

Fig. 5. a) Normal force in vertical cross-section of the wall, b) the bending

checked by a comparison to the development of concrete tensile strength $f_{c t m}(t)$.

On the basis of a two-layer model (in all cases), far greater restrained stress values for the bottom edge of the wall were obtained, than given in Eurocode Standard [3]. This is due to the bending moment as well as the adoption of $R=1.0$. In both approaches [5], [3] following expression (Eq. (7) - for case No. 1) cracking of segment appears, which in practice does not occur. Fig. 6 also shows compressive stresses on the top edge of the segment, which are induced in case of slender foundation.

\section{Cracks control}

In order to satisfy the watertightness criteria the calculations of the necessary amount of reinforcement (in a segment concreted in the first and second stages) for individual cases of ambient temperature were performed. The crack width $w_{k}$ was calculated from the following expression:

$$
w_{k}=S_{r, \max }\left(\varepsilon_{s m}-\varepsilon_{c m}\right)
$$

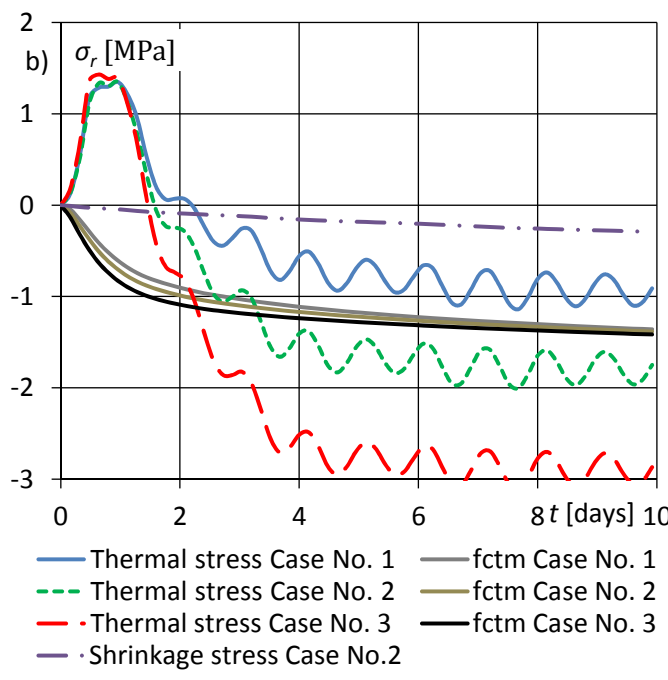

(b)

reflect average daily ambient temperature change by $+7,0$ and $-7^{\circ} \mathrm{C}$ taking place during the concrete hardening phase).

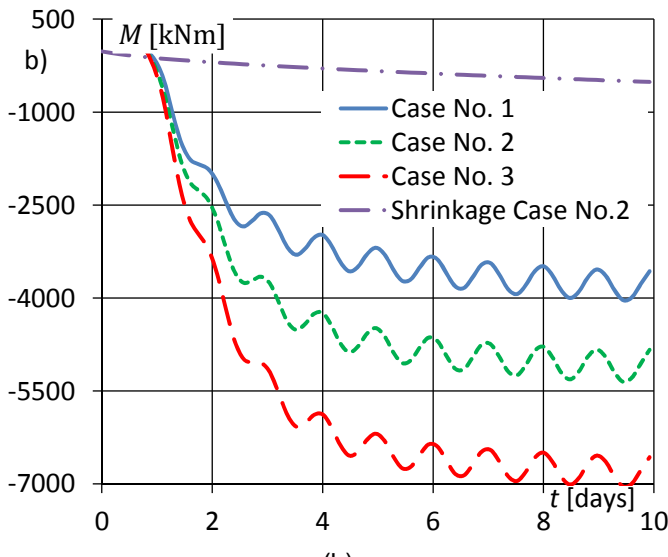

(b)

moment. (Cases 1, 2 and 3 reflect average daily ambient temperature change by $+7,0$ and $-7^{\circ} \mathrm{C}$ taking place during the concrete hardening phase).

The influence of shrinkage and early thermal movements due to cooling of a member, a few days after casting, are considered for two different restraint conditions in the wall, which are: restraint of the member at its ends and restraint along one edge [3]. Both cases are completely different. The former one is found when a new element is cast between two prior-existing elements Eq. (12). This type of restraint is widely described in literature [23] and is quite well understood. The other type of restraint where, for instance, a wall is cast onto a prior-existing base Eq. (13), has not been studied so extensively and is not understood equally well. In this context, stress distribution is affected by the formation of cracks; and the distance between cracks depends on the base and wall geometry as well as the percentage of reinforcement

$$
\varepsilon_{s m}-\varepsilon_{c m}=0,5 \cdot \alpha_{e} \cdot k_{c} \cdot k \cdot f_{c t, e f f} \cdot\left(1+1 / \alpha_{e} \cdot \rho\right) / E_{S}
$$

$$
\varepsilon_{s m}-\varepsilon_{c m}=R \cdot \varepsilon_{\text {free }}
$$




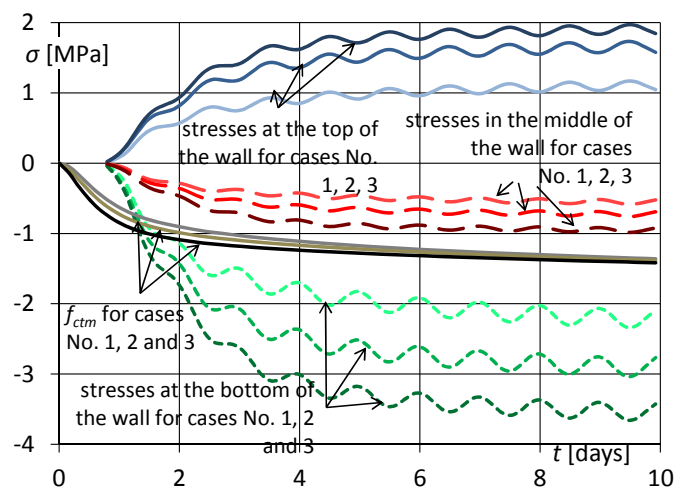

Fig. 6. Stresses in selected areas of the wall for various cases of computing and development of tensile strength. (Cases 1, 2 and 3 reflect average daily ambient temperature change by $+7,0$ and $-7^{\circ} \mathrm{C}$ taking place during the concrete hardening phase).

where: $R$ - a restraint factor, $\varepsilon_{\text {free }}-$ the strain which could occur if the element (wall) was completely unrestrained.

In case of structures where bonded reinforcement is located at reasonably close spacing $\leq 5(c+\varphi / 2)$, the maximum final crack spacing can be calculated from the following expression:

$$
s_{r, \max }=3,4 c+0.425 \cdot k_{1} \cdot k_{2} \Phi / \rho_{p, \text { eff }}
$$

In case of walls subjected to early thermal strains during hardening of concrete whose bottom is restrained by a previously cast base, $s_{r, \max }$ may be assumed to be equal 1.3 times the height of the wall [14]. This rule applies for the walls in which the reinforcement area does not satisfy the requirements of the minimum area of reinforcement. Seruga et al. [13] presented the layout and width of cracks resulting from imposed deformations in a semi-massive cylindrical tank wall. In case of cracking of segments concreted in the first phase (i.e. segments restrained only by the foundation), the width of crack calculated according to the proposed procedure (Eqs. (11), (13), assuming $s_{\text {rmax }}=1.3 \mathrm{H}=7.15 \mathrm{~m}$ and $R_{a x}=0.5$, was $0.894 \mathrm{~mm}$. This represented, respecting the maximum crack width recorded on the segments, overestimation above $200 \%$.

The results obtained following the guidelines (CEN, 2006 [14]) are summarised in Table 1] The direct comparison of the values of $\rho_{\text {eff }}$ (Eqs. (12), (14) ) and (Eqs. (13), (14) indicated the differences to be $260 \%$ for case No. 1. Both cases assume stabilized crack spacing Eq. (14). In such a situation, it is assumed that there will be a restrained deformation large enough, above which further restrained deformation will not result in the formation of next cracks, but will cause an increase in the width of the existing cracks. However, the value of these strains which would appear is unrealistic. This assumption is appropriate from the point of view of external loads exercising a constant force over the entire length of the element, which is not reduced after cracking. For the element subject to imposed load, though, the final crack spacing is much larger than the calculated one because the formation of the next crack is conditioned by an additional increase in the imposed deformation.
Therefore, by applying Eq. 14 crack width should be underestimated. Fig. 7 presents the required degree of reinforcement for the segments concreted in the first stage (Eq. (13), 114) as a function of $\Delta T_{\max }$.

In case of cracking of wall segments concreted in the second stage (i.e. segments restrained at their ends and along the base), there is no standard proposal concerning the determination of $s_{\text {rmax }}$. If the same procedure for the determination of $s_{\text {rmax }}$ as for elements undergoing axial tension is adopted Eqs. (12) (14), then cracks spacing calculated in this way will also be smaller than crack spacing observed in reality. The required amount of reinforcement depending on $\varphi$ and $w_{\text {lim }}$ is shown in Fig. 7p.

To analyse a foundation connected wall the basic assumption of a full restraint along one side is adopted [6]. Moreover, basing on stress distribution in such a model the distance between dilatation cracks was assumed to be $(1.0 \div 1.5) H$. In long plane concrete walls, the crack width is described as follows $w_{2 s}=F_{s} / c_{s}=2\left(\varepsilon_{o} k_{o} H-F_{s} k_{o} H / E_{b} d s\right.$, in which the force value $F_{s}=\varepsilon_{o} k_{o} H /\left(1 / c_{s}+k_{o} H / E_{b} d s\right)$. A general formula to calculate the distance between reinforcing bars was provided, assuming bar diameter $\varphi$ and maximum crack width:

$$
\begin{aligned}
& s=\left(\sqrt{400 \mathrm{~mm}+3,2 \cdot c \cdot \frac{w_{\text {lim }} \cdot k_{o} \cdot H \cdot n \cdot \Phi}{\left(\varepsilon_{0} \cdot k_{o} \cdot H \cdot \beta-w_{\text {lim }}\right) \cdot d}}-\right. \\
& -20 \mathrm{~mm}) \cdot \frac{1.96 \cdot \Phi}{c}
\end{aligned}
$$

where: $c$ - concrete cover $=40 \mathrm{~mm}, k_{o}=1.25, H-$ wall height $=5.5 \mathrm{~m}, n=E_{s} / E_{c m, 28}, \varphi-$ bar diameter, $d$ - wall thickness $=0.45 \mathrm{~m}, \beta=1.42$ (after interpolation), $\varepsilon_{o}$ - concrete strains $=\alpha_{T} \cdot \Delta T$.

Table 2 summarises the results of the necessary amount and percentage of reinforcement for individual cases depending on $\Delta T$ (calculated using this method). The obtained results are similar to the case of the element restrained on opposite edges described in Eurocode Standard [14] Table 1], despite the fact that after [3], this approach does not cover the actually imposed deformations.

The required percentage of reinforcement according to this model, depending on $w_{\text {lim }}$ and $\Delta T_{\text {max }}$, is shown in Fig. 8. In comparison with the required percentage of reinforcement (as a function of $\Delta T_{\text {max }}$ ) in the element restrained at the bottom, after Eurocode Standard [3], this approach gives a much higher percentage of reinforcement. This is primarily caused by a different assumption pertaining to crack spacing.

This model can certainly be used to design very long walls connected with a massive slab, so that the walls are at least partially compatible with the basic assumptions of the model. However, in case of walls restrained by a relatively slender foundation ring, the model will suggest too big reinforcement, especially in the upper part of the wall. The model focuses on the so-called dilatation cracks without separate verification of 
Tab. 1. The summary of reinforcement calculated after [3] for $w_{\text {lim }}=0.1 \mathrm{~mm}$.

\begin{tabular}{|c|c|c|c|c|c|c|c|}
\hline \multirow[t]{2}{*}{ Cases No. } & \multirow{2}{*}{$\begin{array}{c}\Delta T_{\max }+ \\
\Delta T_{c s}\left[{ }^{\circ} \mathrm{C}\right]\end{array}$} & \multicolumn{3}{|c|}{$\begin{array}{l}\text { Segment restrained along one } \\
\text { edge Eq. 13, }\end{array}$} & \multicolumn{3}{|c|}{$\begin{array}{l}\text { Segment restrained at it ends and } \\
\text { bottom edge Eq. (12, } 14\end{array}$} \\
\hline & & $\varphi 20 \mathrm{~mm}$ at & $\rho_{e f f}[\%]$ & $\rho[\%]$ & $\varphi 20 \mathrm{~mm}$ at & $\rho_{e f f}[\%]$ & $\rho[\%]$ \\
\hline 1 & $15+2$ & $0.345 \mathrm{~m}$ & 0.73 & 0.41 & $0.110 \mathrm{~m}$ & 2.28 & 1.27 \\
\hline 2 & $20+2$ & $0.255 \mathrm{~m}$ & 0.99 & 0.55 & $0.106 \mathrm{~m}$ & 2.37 & 1.32 \\
\hline 3 & $26.5+2$ & $0.185 \mathrm{~m}$ & 1.36 & 0.75 & $0.101 \mathrm{~m}$ & 2.48 & 1.38 \\
\hline
\end{tabular}

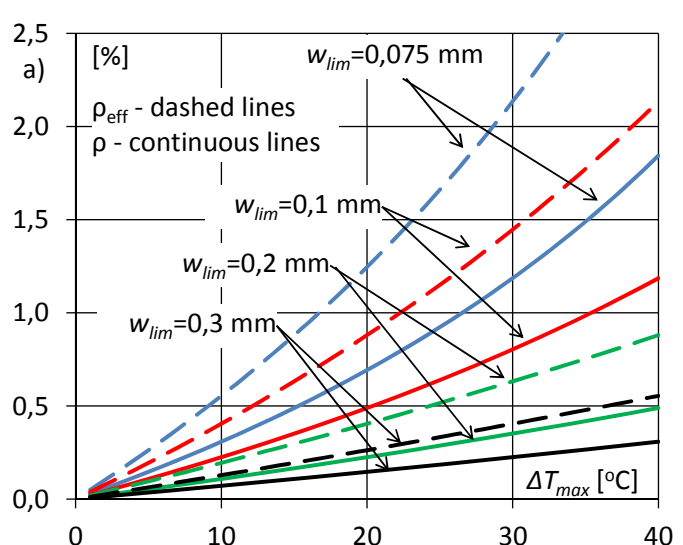

(a)

Fig. 7. a) The required percentage of reinforcement in the restrained element

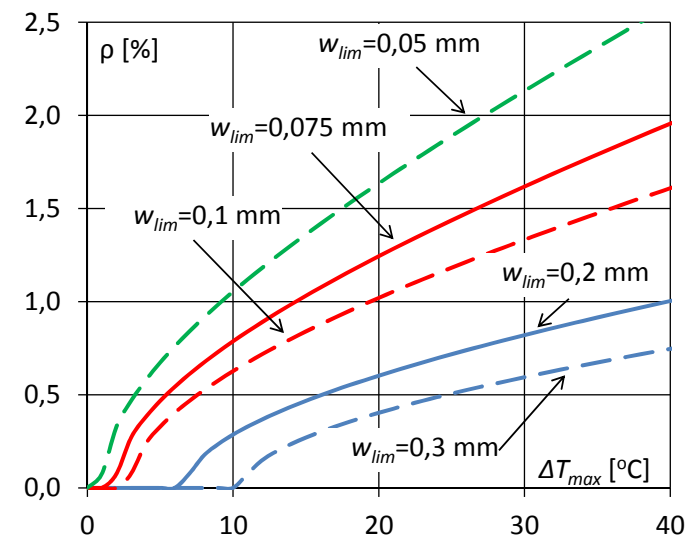

Fig. 8. Reinforcement percentage after [6] determined for the analysed segment wall depending on $w_{\text {lim }}$ and $\Delta T_{\max }$.

cracks which do not reach the upper edge of the wall, which may also be the source of considerable leakage of the tank.

The criterion of thermal cracks appearance during the cooling phase of the wall can be expressed as follows: $\varepsilon_{o}(t) \leq$ $f_{c t m}(t) / E_{w}(t)$. Following [5], stresses in steel reinforcement and crack width for a stable crack pattern are described as follows:

$$
\begin{gathered}
\sigma_{s r e}=\frac{f_{c t m}}{\rho} \cdot \frac{m_{D e} \cdot \bar{v}_{0}}{1+\frac{2 l_{E m}}{3 H n \rho}} \\
w_{s r e}=\frac{2 f_{c t m}}{3 E_{s} \rho} \cdot \frac{m_{D e} \cdot \bar{v}_{0}}{1+\frac{2 l_{E m}}{3 H n \rho}} l_{e m}
\end{gathered}
$$

where: $\rho$-degree of reinforcement, $l_{E m}$ - length of relaxation

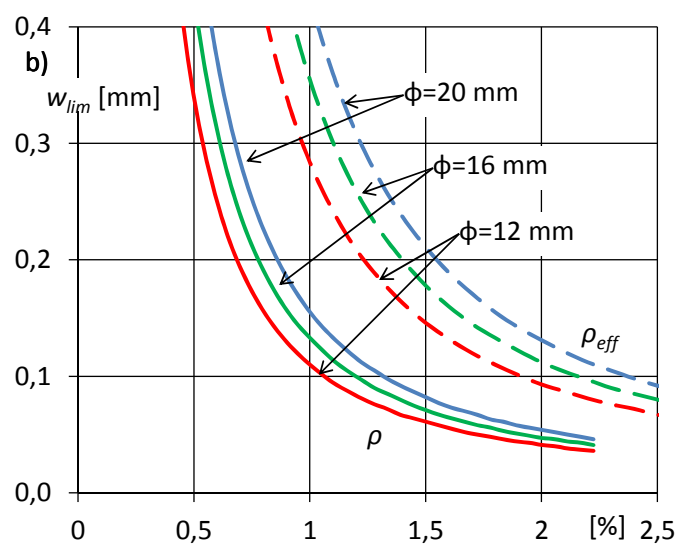

(b)

at the bottom edge as a function of $\Delta T_{\max }$ for individual values of $w_{\text {lim }}, \mathrm{b}$ ) the required percentage of reinforcement in the element restrained at both ends.

zone, $\bar{v}_{o}$ - half crack width in concrete element, $m_{D e}$ - parameter describing stable state of cracking.

Based on expressions (16), (17) a general formula for the calculation of the distance between reinforcing bars was provided, assuming bar diameter $\varphi$, maximum crack width and parameter $m_{D e}$

$$
\begin{aligned}
& s=\phi\left(1,2-0,12 \frac{c}{\phi}\right) \cdot\left(1,54 \sqrt{\frac{n \cdot H}{b}}\right. \\
& \left.\sqrt{\frac{w_{l i m} \cdot E_{s}}{\beta \cdot f_{c t m} \cdot H \cdot n \cdot m_{D e} \cdot \bar{v}_{o}-w_{l i m} \cdot E_{s}}}-\frac{c}{2 \phi}\right)
\end{aligned}
$$

The above expression is valid when the condition is fulfilled:

$$
H \geq \min H=w_{\text {lim }} \cdot E_{s} / \beta \cdot f_{c t m} \cdot n \cdot m_{D e} \cdot \bar{v}_{o}
$$

This model does not include the weight of the structure, stresses redistribution and the type of the ground. In all cases, Eq. (19) was satisfied under the assumption of $\varepsilon$ as in Eq. (7) (see Fig. 9a). Adopting $w_{\text {lim }}=0.1 \mathrm{~mm}$, the calculated amount of reinforcement Eq. (18) for individual cases is as summarised in Table 2

Fig. 9a shows that in all cases the cracks appeared in the early age of concrete. Fig. 9 p shows the development of crack height for individual cases. It should be noted that in case No. 1, in fact, there will be no cracks, because of the compression stresses which appeared with temperature increase. However, this plot illustrates the effect of external conditions (also indirectly the 
Tab. 2. The summary of the calculated reinforcement after [5] [6] for $w_{\text {lim }}=0.1 \mathrm{~mm}$.

\begin{tabular}{ccccccc}
\hline & & \multicolumn{2}{r}{ Iványi [6 } & \multicolumn{2}{c}{ Rostásy et al. } & \\
\cline { 3 - 6 } Cases No. & $\Delta T_{\max }+\Delta T_{c s}\left[{ }^{\circ} \mathrm{C}\right]$ & $\varphi 20 \mathrm{~mm}$ at & $\rho[\%]$ & $\varphi 20 \mathrm{~mm}$ at & $\rho[\%]$ \\
\hline 1 & $15+2$ & $0.13 \mathrm{~m}$ & 1.08 & $0.16 \mathrm{~m}$ & 0.87 \\
\hline 2 & $20+2$ & $0.11 \mathrm{~m}$ & 1.26 & $0.13 \mathrm{~m}$ & 1.05 \\
\hline 3 & $26.5+2$ & $0.10 \mathrm{~m}$ & 1.47 & $0.11 \mathrm{~m}$ & 1.27 \\
\hline
\end{tabular}

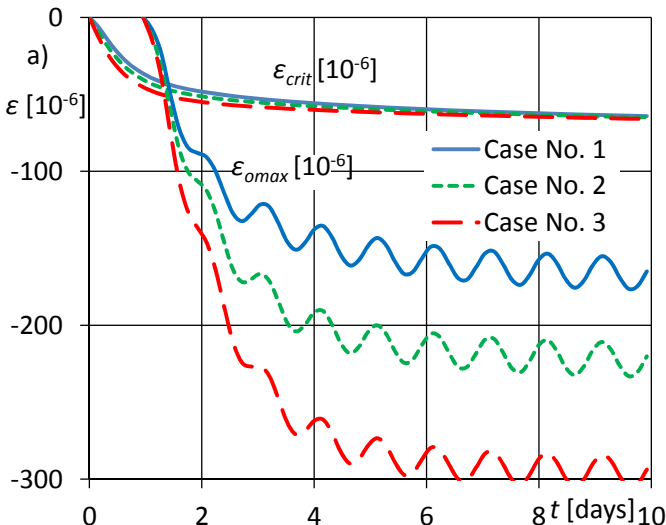

(a)

Fig. 9. a) Maximum and ultimate concrete strains, b) crack height for an individual case of computing. (Cases 1,2 and 3 reflect average daily ambient

decisions of the contractor) on a possibly different degree of segment cracking, as the segments were designed and made in the same way. It should, then, be concluded that there is a need to concreting at another time, due to extremely adverse weather conditions. These guidelines should be determined by the designer and based on the analysis of possible effects, i.e. a large number of leakages and required numerous repairs, applying the amount of reinforcement economically justified.

Fig. 10 shows the required percentage of reinforcement (for concrete parameters from Case No. 2), determined by the twolayer model as a function of $\Delta T_{\max }$ for different values $w_{\text {lim }}$. In other computing cases ( 1 and 3 ) the differences in the results are not greater than $1 \%$. Accepting large values of $\Delta T_{\max }$ requires a high and not economically justifiable percentage of reinforcement. From the point of view of the designer, the value of $\Delta T_{\max }$ must be specified together with the permissible ambient conditions in which concreting can proceed.

\section{Comparison with experimental investigation in a nat- ural scale}

The reservoir was completed in the summer months, under varied ambient conditions. In the first stage, the even numbered segments were concreted, and in the second stage the odd numbered ones. Steel A-III N $\left(f_{y d}=420 \mathrm{MPa}\right)$ was used. In the circumferential direction on the inside surface of the wall the following were applied $\varphi 16 \mathrm{~mm}$ bars with centre-to-centre spacing $0.125 \mathrm{~m}$ to the height of $2.80 \mathrm{~m}(\rho=0.71 \%)$, and further $\varphi 12 \mathrm{~mm}$ bars with centre-to-centre spacing $0.125 \mathrm{~m}$ to the upper edge of the wall. The outside surface of the wall was reinforced by $\varphi 20 \mathrm{~mm}$ bars with centre-to-centre spacing $0.1 \mathrm{~m}$

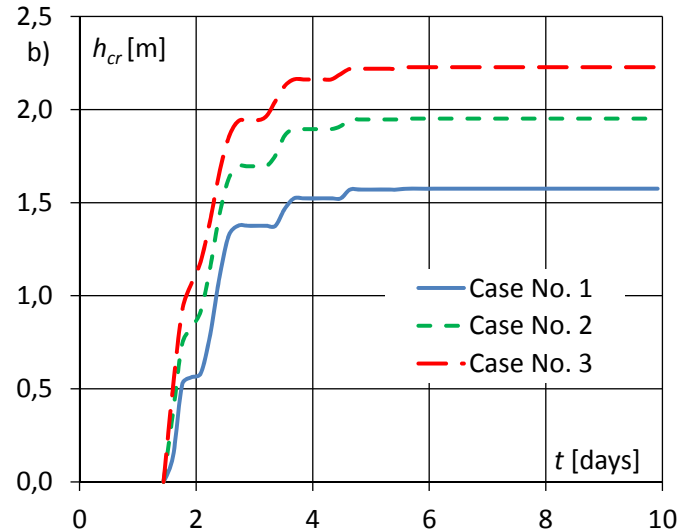

(b)

temperature change by $+7,0$ and $-7^{\circ} \mathrm{C}$ taking place during the concrete hardening phase).

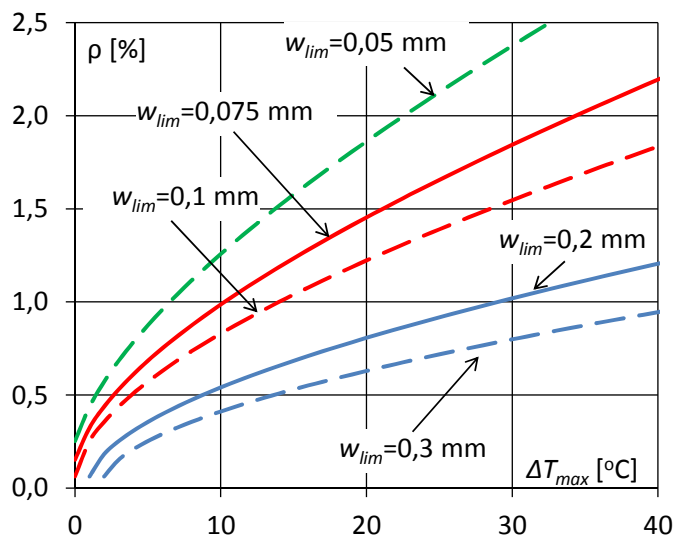

Fig. 10. Reinforcement percentage after [5], determined for the analysed segment wall depending on $w_{\text {lim }}$ and $\Delta T_{\max }$.

( $\rho=1.40 \%$ ) at the height of 0.0 to $1.20 \mathrm{~m}$, then the bars $\varphi 16 \mathrm{~mm}$ with centre-to-centre spacing $0.10 \mathrm{~m}(\rho=0.90 \%)$ up to $2.5 \mathrm{~m}$, and further $\varphi 12 \mathrm{~mm}$ bars with centre-to-centre spacing $0.10 \mathrm{~m}$. A detailed drawing of the tank reinforcement of the same type was shown in [24].

Figs. 11 and 12 show the cracking of selected segments, i.e. No. 8 and No. 1, respectively. The layout of cracks on the inner surfaces of wall segments were inventoried in two periods: July 15 (stage I - Figs. 11 1 , 12 a) and September 15 (stage II - Figs. 11p, 12p). The crack width located on the outer surface of the segments was measured only in the second stage (Figs. 11, 12, ). On segment No. 8 three through cracks were found (Fig. 11]), and on segment No. 1 six through cracks occurred (Fig. 12 $\mathrm{d}$ ). During the watertightness test, leakages on all the through cracks were reported. These segments were con- 
creted at the ambient temperatures of up to $28^{\circ} \mathrm{C}$ (measured in the shade), which increased the maximum temperature in the wall up to $45^{\circ} \mathrm{C}$ and contributed to the growth of $\Delta T_{\max }$.

Fig. 13 shows the calculations for individual places of wall reinforcement, i.e. $\rho=1.40 \%, 0.90 \%$ and $0.71 \%$, estimating the crack width depending on $\Delta T_{\max }$. Assuming even $\Delta T_{\max }=40^{\circ} \mathrm{C}$ and $\rho=1.40 \%$, the maximum crack width on the outer surface of the wall after (CEN, 2006 [3]) should not exceed $0.09 \mathrm{~mm}$; following [5], [6] it may reach the value of $0.15 \mathrm{~mm}$ and $0.125 \mathrm{~mm}$. A direct comparison of the calculated values with the measurements is impossible, but after two months the maximum crack width was $0.15 \mathrm{~mm}$ (Figs. 11, $12 \mathrm{k}$ ). In case of a higher wall zone, on the outer surface $\left(\rho=0.90 \% ; \Delta T_{\max }=40^{\circ} \mathrm{C}\right)$ after (CEN, 2006 [3]), the maximum crack width should not exceed $0.12 \mathrm{~mm}$ (for the segment restrained along the bottom edge) and $0.16 \mathrm{~mm}$ (for the segment restrained along three edges). In [5], the widths are $0.2 \mathrm{~mm}$, which was found to be consistent with the observations. In [6] this value is overestimated and is $0.25 \mathrm{~mm}$.
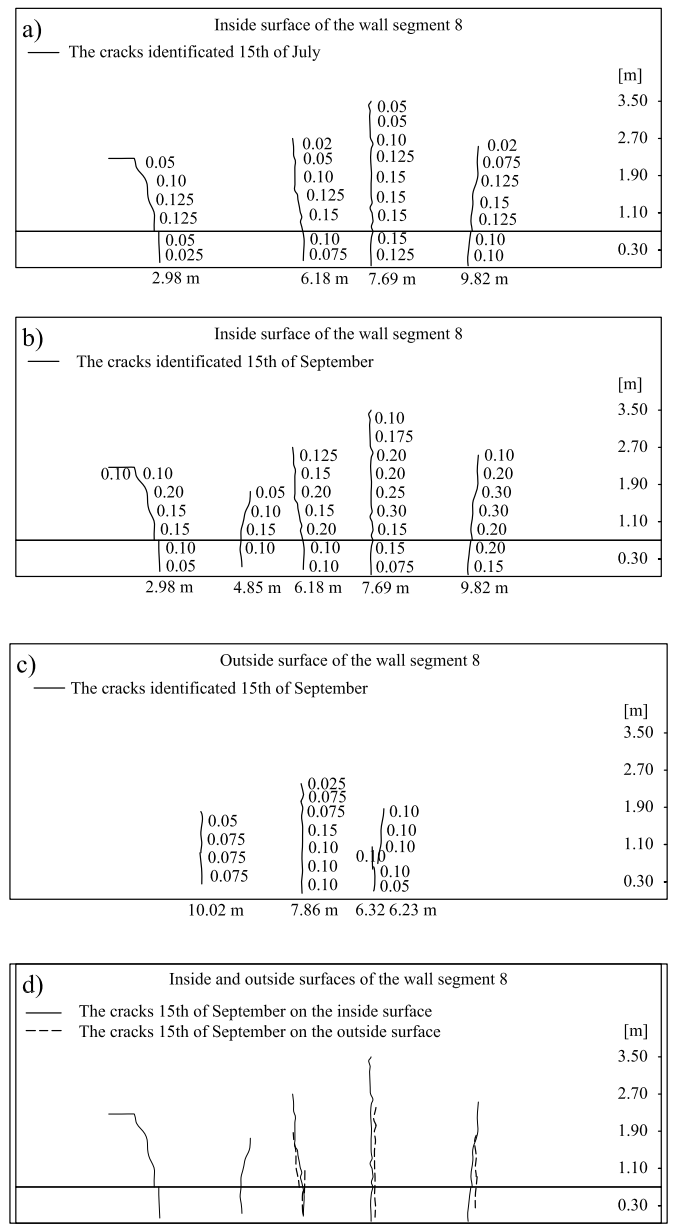

Fig. 11. Cracks on segment No. 8 restrained along one edge.

In case of the internal surfaces $(\rho=0.71 \%)$, the maximum crack width should not be greater than $0.15 \mathrm{~mm}$ (for the segment restrained along the bottom edge) and $0.23 \mathrm{~mm}$ (for the segment restrained along three edges), while according to [6] and [5] it should be 0.27 and $0.40 \mathrm{~mm}$, respectively. The measurements of segment No. 8 during concrete hardening showed the value
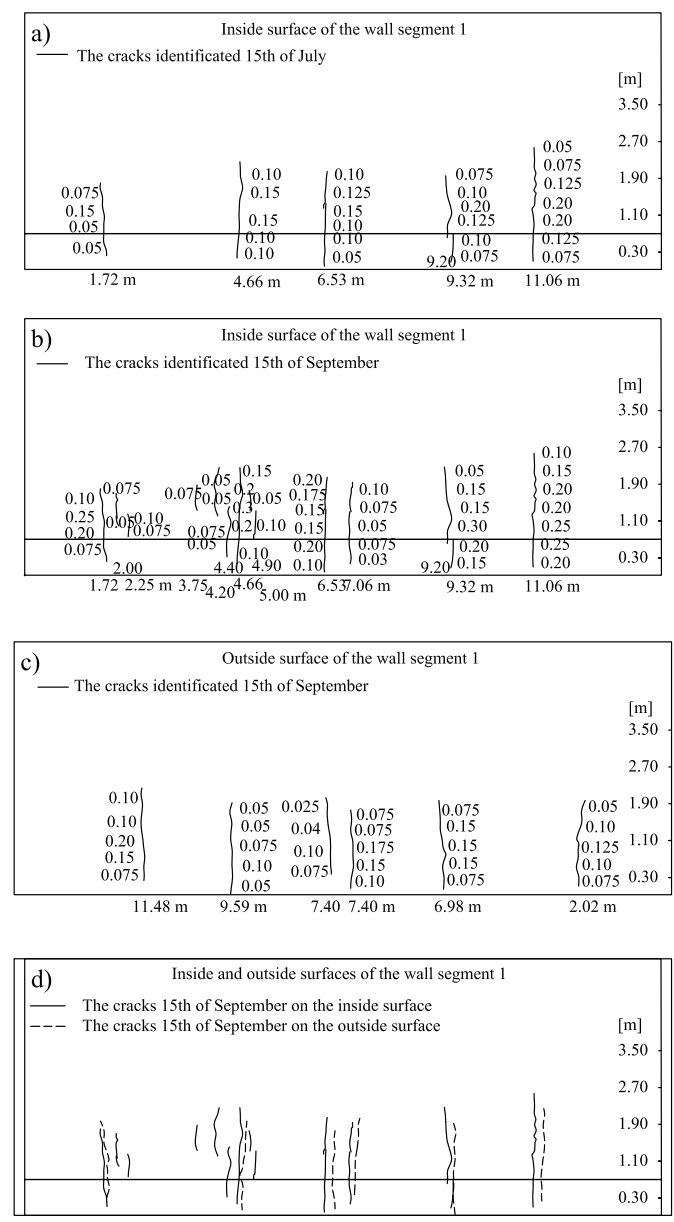

Fig. 12. Cracks on segment No. 1 restrained at its ends and the base.

of $0.15 \mathrm{~mm}$ and the subsequent expansion up to $0.3 \mathrm{~mm}$. However, in case of segment No. 1 (restrained along three edges) in the early age of hardening, the measured crack width was $0.2 \mathrm{~mm}$ and it expanded up to $0.3 \mathrm{~mm}$. Although this comparison was made for $\Delta T_{\max }=40^{\circ} \mathrm{C}$, in case of crack width given in Eqs. (13) and (14), it is significantly understated. A model (Rostásy and Henning, 1989 [5]) shows a definitely better prediction of the crack width. Moreover, according to (Ivanyi, 1995 [6]), the crack width is again overestimated.

The crack width values in the tank wall segments were added for each measurement period separately (Fig. 14). As results from the data presented, the largest cracks on the inner and outer surfaces of the segments were recorded at the height of $0.9 \div 1.7 \mathrm{~m}$ and $0.7 \div 1.1 \mathrm{~m}$, respectively. This specifies the localisation of initial cracks and the need for a proper amount of reinforcement especially in those places.

Next, the temperature change was calculated for each of ten segments of the tank which were made at different ambient temperatures and varying initial temperature of the concrete mix (Seruga et. al, 2008 [13]). Fig. 15 shows the results of average temperature changes, taking into account the ambient conditions and formwork removed after 24 hours. For such calculated temperature changes, the temperature difference $\Delta T_{\max }$ in the cross-section of the wall was calculated up to the fifth day after segment concreting (see Table 3). Moreover, Table 3 sum- 


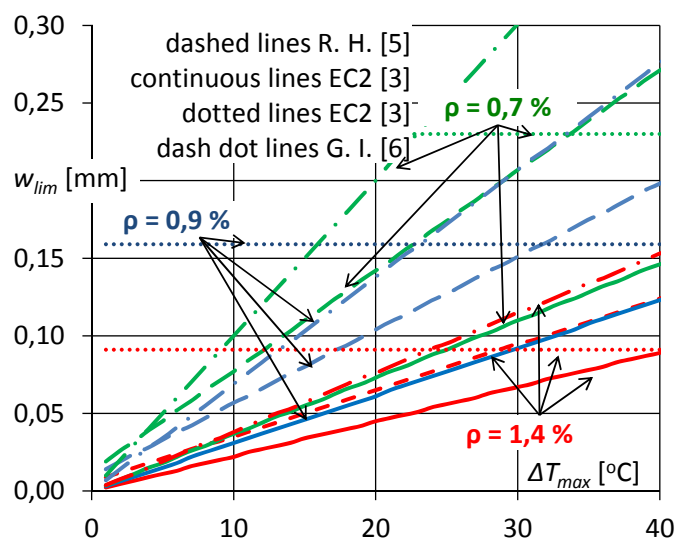

Fig. 13. Crack width depending on: $\Delta T_{\max }$ and the assumed percentage of reinforcement.

marises cracks widths measured for individual segments on their inner surface (in the first and second measuring steps), and on their outer surface in the second measuring step. On this basis it can be concluded that the bigger the temperature drop during the first five days of wall hardening, the larger the maximum crack width. A detailed layout of cracks was presented in [13]. The succeeding rows of Table 3 present the calculated crack width according to particular models for the percentage of reinforcement of $0.71 \%$ (inner surface) and for the percentage of $0.90 \%$ and $1.40 \%$ (outer surface).

Calculations after [3] Eqs. (13) (14) point to a significant impact of temperature difference on the calculated crack width, while then impact of reinforcement percentage on the reduction of their width is very small. Comparing the cracks formed on the inner surface in the first step, they are considerably wider than the calculated ones, i.e. 2.3 times on average. Moreover, these cracks, compared with the first step of measurement, increase by about $53 \%$. So, the use of these expressions can lead to significant underestimation of crack width.

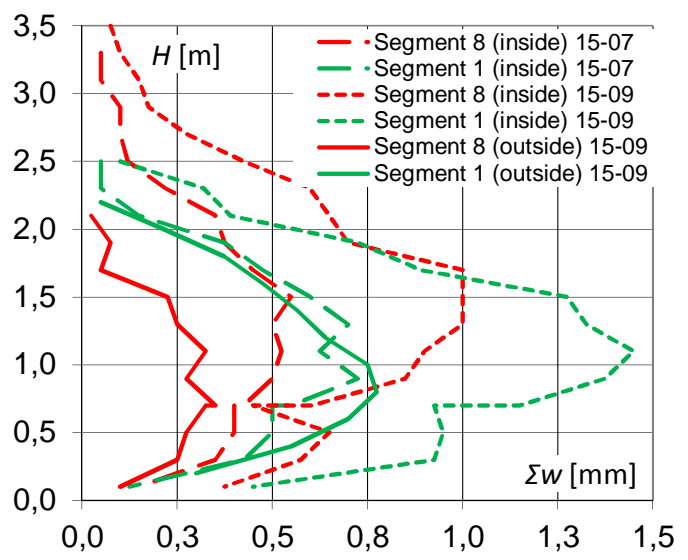

Fig. 14. The sum of the measured crack widths in segments No. 8 and 1 as a function of segment height $H$.

In the second case of the calculation, i.e. Eqs. (12), (14) after [3] the level of strain changes from temperature and shrinkage are neglected, and for a selected concrete class the crack width is dependent on reinforcement percentage. Therefore, these formulae overestimate the crack width on the inner surface in the

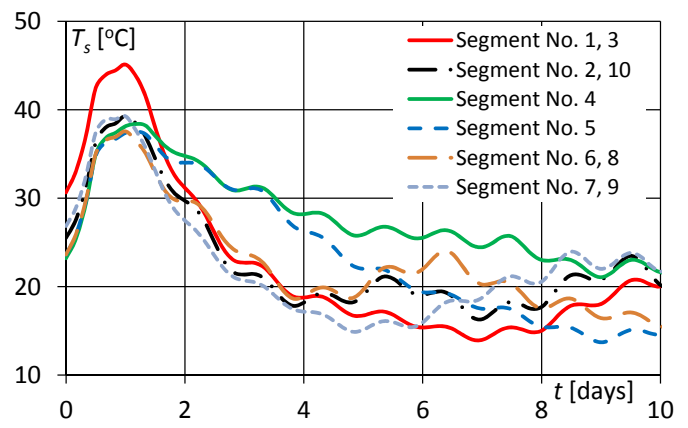

Fig. 15. Calculated mean temperature in the cross-section of each segment.

first stage by $35 \%$ on average, while for the second stage they underestimate it by $11 \%$ on average.

In case of the model [6] the overestimation of crack width (in the first stage of measurement) on the inner surface is $45 \%$. But in comparison with crack width formed in the second stage, this model gives values underestimated by about $5 \%$ on average.

Model [5], in turn, for the case of the inner surface gives a very good approximation for concrete maturing stage, because the underestimation of the cracks width is $7 \%$. In this model, in analogy to [6], smaller crack spacing, as a result of further imposed deformations, is disregarded.

Comparing the measured crack widths, it can be concluded that the maximum crack width during concrete maturing is further widened by up to $100 \%$ (segment No. 8 ). This is caused by both concrete shrinkage and further decrease of ambient temperature. In addition, Eqs. (12), (14), according to [3], even for stabilised crack spacing would underestimate their width.

The engineering models [6], [5], approximate the width of cracks formed during concrete maturing stage much more accurately than the recommendations of [3], in case of both Eqs. (12), (14) and (12) (13). In addition, it should be emphasised that the sum of crack width measured on the inner surface of the segments on September 15, i.e. after 60 days, was significantly bigger in relation to the sum of crack width measured in the first stage. These changes are undoubtedly caused by drying shrinkage and the behaviour of the whole tank after its completion, during its exposure to lower ambient temperatures. The existing cracks developed at the height of the wall, increasing in width at lower levels. Some new cracks appeared as well.

\section{Conclusions}

The main technical effect:

The influence of external weather conditions on crack width during the period of concrete maturing is a dominating factor. Consequently, even though a high percentage of reinforcement is implemented, watertightness condition might not be fulfilled. This situation occurs when concreting is performed in a higher ambient temperature which, during a few days, stabilises at a lower level (Case No 3). It is best to concreting in the period of low ambient temperatures and their further stabilisation at a higher level. Such weather conditions shall be regarded as favourable (Case No 1). On the other hand, concreting in sta- 
Tab. 3. The summary of the calculated cracks widths for each segment including different models in comparison with measured values [mm].

\begin{tabular}{|c|c|c|c|c|c|c|c|c|}
\hline \multicolumn{2}{|c|}{ Segment No. } & 1,3 & 2,10 & 4 & 5 & 6 & 8 & 7,9 \\
\hline \multicolumn{2}{|c|}{$\Delta \mathbf{T}_{\max }+\Delta \mathbf{T}_{\mathrm{cs}}\left[{ }^{\circ} \mathrm{C}\right]$ (up to 5 days) } & 30.4 & 23.5 & 17.2 & 17.5 & 21.9 & 20.9 & 26.4 \\
\hline \multirow{3}{*}{$\begin{array}{l}\text { Measured } \\
w_{\max }[\mathrm{mm}]\end{array}$} & \multirow{2}{*}{ inside } & 0.20 & 0.15 & - & - & 0.15 & 0.15 & 0.20 \\
\hline & & 0.30 & 0.20 & - & - & 0.20 & 0.30 & 0.30 \\
\hline & outside & 0.20 & 0.15 & - & - & 0.10 & 0.15 & 0.13 \\
\hline \multirow{3}{*}{$\begin{array}{l}\text { EC2 } 3 \\
\text { Eq. } 13,14 \\
\end{array}$} & inside & 0.09 & 0.07 & 0.05 & 0.05 & 0.07 & 0.06 & 0.08 \\
\hline & \multirow{2}{*}{ outside } & 0.08 & 0.06 & 0.04 & 0.04 & 0.06 & 0.06 & 0.07 \\
\hline & & 0.07 & 0.05 & 0.04 & 0.04 & 0.05 & 0.05 & 0.06 \\
\hline \multirow{3}{*}{$\begin{array}{c}\text { EC2 } 3 \\
\text { Eq. (12) } 14 \\
\end{array}$} & inside & 0.23 & 0.23 & 0.23 & 0.23 & 0.23 & 0.23 & 0.23 \\
\hline & \multirow{2}{*}{ outside } & 0.16 & 0.16 & 0.16 & 0.16 & 0.16 & 0.16 & 0.16 \\
\hline & & 0.09 & 0.09 & 0.09 & 0.09 & 0.09 & 0.09 & 0.09 \\
\hline \multirow{3}{*}{ Iványi 6} & inside & 0.30 & 0.24 & 0.17 & 0.17 & 0.22 & 0.21 & 0.26 \\
\hline & \multirow{2}{*}{ outside } & 0.21 & 0.16 & 0.12 & 0.12 & 0.15 & 0.14 & 0.18 \\
\hline & & 0.12 & 0.09 & 0.07 & 0.07 & 0.08 & 0.08 & 0.10 \\
\hline \multirow{3}{*}{$\begin{array}{c}\text { Rostásy, } \\
\text { Henning } 5\end{array}$} & inside & 0.20 & 0.15 & 0.11 & 0.11 & 0.14 & 0.13 & 0.17 \\
\hline & \multirow{2}{*}{ outside } & 0.14 & 0.11 & 0.08 & 0.08 & 0.10 & 0.10 & 0.12 \\
\hline & & 0.09 & 0.07 & 0.05 & 0.05 & 0.06 & 0.06 & 0.08 \\
\hline
\end{tabular}

ble weather conditions (Case No 2) does not guarantee avoiding cracking. That is why the constructor's decisions pertaining to concreting in unfavourable weather conditions have the main impact on the degree of cracking in RC walls.

Crack spacing varies considerably. More cracks develop in the segments concreted in the second stage and they are definitely longer and wider than those in the segments concreted in the first stage. Crack width increase during the first 60 days on segments no 8 and 1, 100 and 50\% accordingly. It shows a significant problem disregarded at the design stage.

The main scientific effect:

The way of crack calculation defined in Annex M [3], in case of tank walls concreted in the first stage leads to underestimating the crack width in comparison with the crack width observed. It results from Eq. (14) assuming stabilised crack spacing similarly as for bar elements loaded by external force. In this way, the crack spacing obtained according to the Eq. (14) is smaller in comparison with the one observed in practice. Assuming $s_{r, \max }=1.3 \mathrm{H}$ will lead to crack width double overestimation (Seruga et. al, 2008 [13]). The engineering models [6], [5] definitely seem to be a safer calculation approach [5].

According to EC2-3 [3] the type of element restrain at the same level of imposed strain leads to a very big difference in reinforcement area which is required to limit crack width. In the wall restrained by the foundation, the change of imposed strain has the main influence on crack width. Imposed strain size influence directly the reinforcement area required. In case of the element restrained at its ends, the reinforcement area is defined mainly by concrete mechanical properties. Moreover, EC2-3 [3] does not consider the change in the wall restrain scheme deriving from concreting subsequent segments.

The widest crack was observed on the outer and inner surfaces at the height of $0.9 \div 1.7 \mathrm{~m}$ and $0.7 \div 1.1 \mathrm{~m}$, respectively. It indicates the area of crack initiation and the need of proper reinforcement of these places.

\section{References}

1 Wu S, Huang D, Lin FB, Zhao H, Wang P, Estimation of cracking risk of concrete at early age based on thermal stress analysis, $\mathrm{J}$ Therm Anal Calorim, 105(1), (2011), 171-186, DOI 10.1007/s10973-011-1512-y

2 Azenha M, Lameiras R, de Sousa C, Barros J, Application of air cooled pipes for reduction of early age cracking risk in a massive $R C$ wall, Engineering Structures, 63(14), (2014), 148-163, DOI 10.1016/j.engstruct.2014.01.018

3 Eurocode 2, Design of concrete structures - Part 3: Liquid retaining and containment structures, European Committee for Standardization; CEN, Brussels, 2006

4 Stoffers $\mathbf{H}$, Cracking due to shrinkage and temperature variation in walls, Delft University of Technology and I.B.B.C.; Delft, 1978.

5 Rostásy FS, Henning W, Zwang in Stahlbetonwänden auf Fundamenten, Imposed loads in walls on the foundation, Beton- und Stahlbetonbau, 84(8), (1989), 208-214, DOI 10.1002/best.198900300

6 Iványi G, Bemerkungen zu Mindestbewehrung in Wänden, Minimum reinforcement in the walls, Beton- und Stahlbetonbau, 90(11), (1995), 283-289, DOI 10.1002/best.199500460

7 Paas U, Mindestbewehrung für verformungsbehinderte Betonbauteile im jungen Alter, Minimum reinforcement in restrainet concrete elements at a young age, Deutscher Ausschuss für Stahlbeton, 1998.

8 ACI 207.2 R-95, Volume Change, and Reinforcement on Cracking of Mass Concrete, American Concrete Institute; ACI, Detroit, USA, 1995.

9 ACI 207.2 R-07, Report on thermal and volume change effects on cracking of mass concrete, American Concrete Institute; ACI, Detroit, USA, 2007.

10 Zych M, Analiza pracy ścian zbiorników żelbetowych we wczesnym okresie dojrzewania betonu, $w$ aspekcie ich wodoszczelności, Analysis of RC tank's walls during early hardening period of concrete, in aspect of water watertightness, PhD thesis, Cracow University of Technology; Cracow, Poland, 2011,http://suw.biblos.pk.edu.pl/resources/i3/i8/i7/ i0/r3870/ZychM_AnalizaPracy.pdf

11 Byard BE, Schindler AK, Modeling early-age stress development of restrained concrete, Materials and Structures, 48(1-2), (2015), 435-450, http: //link.springer.com/article/10.1617/s11527-013-0194-2 DOI 10.1617/s11527-013-0194-2

12 Buffo-Lacarriere L, Sellier A, Turatsinze A, Escadeillas G, Finite ele- 
ment modelling of hardening concrete, Application to the prediction of early age cracking for massive reinforced structures, Materials and Structures, 44(10), (2011), 1821-1835, DOI 10.1617/s11527-011-9740-y

13 Seruga A, Szydłowski R, Zych M, Ocena postepujacego procesu zarysowania ścian cylindrycznych $w$ monolitycznych zbiornikach żelbetowych, The evaluation of sequential process of cracking of wall segments in monolithic cylinder reinforcement concrete tank, Technical Transactions, Civil Engineering, 21(1), (2008), 135-163, http: //suw . biblos . pk . edu . $\mathrm{pl} /$ resourceDetails\&rId $=830$

14 Eurocode 2, Design of concrete structures-Part 1-1: General rules and rules for buildings, European Committee for Standardization; CEN, Brussels, 2004.

15 Wang J, Yan P, Evaluation of early age mechanical properties of concrete in real structure, Computers and Concrete, 12(1), (2013), 53-64, DOI 10.12989/cac.2013.12.1.053

16 Maruyama I, Teramoto A, Igarashi G, Strain and thermal expansion coefficients of various cement pastes during hydration at early ages, Materials and Structures, 47(1-2), (2014), 27-37, DOI 10.1617/s11527-013-0042-4

17 Yeon J, Choi S, Won M, In situ measurement of coefficient of thermal expansion in hardening concrete and its effect on thermal stress development, Constr Build Mater, 38(36), (2013), 306-315, DOI 10.1016/j.conbuildmat.2012.07.111

18 Klemczak B, Prediction of coupled heat and moisture transfer in early-age massive concrete structures. Numerical heat transfer part A: Applications, An International Journal of Computation and Methodology, 60(3), (2011), 212-233, DOI 10.1080/10407782.2011.594416

19 Häußler U, Hartig J, Evaluation of Concrete Cracking due to Restrained Thermal Loading and Shrinkage, ACI Structural Journal, 109(1), (2012), 41-52, http://www.concrete.org/Publications/ ACIMaterialsJournal/ACIJournalSearch.aspx?m=details\&ID= 51683493 DOI $10.14359 / 51683493$

20 BS 8007, Design of concrete structures for retaining aqueous liquids, British Standards Institution; London, Great Britain, 1987.

21 Kiernożycki W, Betonowe konstrukcje masywne, Concrete massive structures, Polish Cement; Cracow, Poland, 2003.

22 Flaga K, Napręzenia skurczowe $i$ zbrojenie przypowierzchniowe $w$ konstrukcjach betonowych, Shrinkage stress and reinforcement in concrete structure, Monograph 295, Cracow University of Technology; Cracow, Poland, 2011, http://www.wydawnictwo.pk.edu.pl/books/view/333

23 Lewiński P, Zasady projektowania zbiorników żelbetowych na ciecze z uwzglednieniem wymagan Eurokodu 2, Principles for the design of reinforced concrete tanks for liquids, taking into account the requirements of Eurocode 2, Institute for Building Technology; Warsaw, Poland, 2011.

24 Seruga A, Zych M, Thermal cracking of the cylindrical tank under construction. I: Case study, ASCE Journal of Performance Construction Facilities, (2014), DOI 10.1061/(ASCE)CF.1943-5509.0000581 